\title{
Heat shock results in cell cycle delay and synchronisation of mitotic domains in cellularised Drosophila melanogaster embryos
}

\author{
Gabriela Maldonado-Codina, Salud Llamazares and David M. Glover* \\ Cancer Research Campaign Laboratories, Cell Cycle Genetics Group, Department of Anatomy and Physiology, Medical \\ Sciences Institute, University of Dundee, Dundee DD14HN, Scotland \\ *Author for correspondence
}

\section{SUMMARY}

Cells of Drosophila embryos that are subjected to a $37^{\circ} \mathrm{C}$ temperature shock whilst undergoing the $S$-phase of cell cycle 14 arrest with their microtubules in an interphaselike state, and with nuclei showing unusual chromatin condensation. They do not recover from this state within a 30 minute period even though extensive gastrulation movements can occur. Cells of embryos heat shocked in $\mathbf{G}_{2}$-phase are delayed in interphase with high levels of cyclins $A$ and $B$. Within ten minutes recovery from heat shock, cells enter mitosis throughout the embryo. The degradation of the mitotic cyclins $A$ and $B$ in these synchronised mitotic domains does not follow the normal timing, but is delayed. These findings point to a need for caution when interpreting experiments that use the heat shock promoter to study the expression of cell cycle control genes in Drosophila.

Key words: heat shock, cell cycle delay, mitotic domains, Drosophila melanogaster embryo

\section{INTRODUCTION}

The effects of heat shock upon gene expression were first discovered in Drosophila, with the finding that temperature elevation or treatment with a number of chemicals could bring about a new puffing pattern on polytene chromosomes (Ritossa, 1962) indicative of the induced expression of a small number of genes. Following a shift from $25^{\circ} \mathrm{C}$ to $37^{\circ} \mathrm{C}$, there is a general decrease in ongoing transcription and translation, and transcription is redirected to the synthesis of heat shock mRNAs, the most abundant of which is the mRNA encoding a $70 \mathrm{kDa}$ heat shock protein ( $h s p 70)$ (Tissières et al., 1974; McKenzie et al., 1975; Spradling et al., 1977; McKenzie and Meselson, 1977; see Pauli et al., 1992 for review).

It has also been known for some time that if Drosophila embryos are heat shocked around blastoderm or gastrulation, this can result in a number of developmental defects resembling known mutant phenotypes and known as phenocopies (Goldschmidt, 1935; Gloor, 1947). Foe and Alberts (1985) have examined the effects of administering heat shock to early Drosophila embryos. The Drosophila embryo is a syncytium for the first 13 divisions which occur at approximately 10 minute intervals, and which consist of rapidly alternating $\mathrm{S}$ - and $\mathrm{M}$-phases (Foe and Alberts, 1983). A $\mathrm{G}_{2}$-phase is introduced following cellularisation which occurs in the 14th cycle. Cell divisions then occur within a series of spatially and temporally regulated domains (Foe, 1989). When Foe and Alberts (1985) sub- jected syncytial embryos to a $37^{\circ} \mathrm{C}$ heat shock they found that nuclei arrest in interphase, swell and show abnormal condensation of their chromatin. If mid-cycle 14 embryos were subjected to the same treatment, they show no such effect and were thought to be protected from the effects of the heat shock by hsps that can be synthesised from this developmental stage onwards. In cultured Drosophila cells, however, heat shock appears to affect the organisation of the centrosome, and its ability to nucleate microtubules (Debec et al., 1990).

The high levels of heat induced expression from the hsp70 promoter have made it attractive for examining the conditional expression of a large number of cloned genes in transformed flies. Edgar and O'Farrell (1990) showed that when this promoter was used to drive the ectopic expression of the cell cycle regulatory gene string (stg), mitosis no longer occurred in domains, but cells entered mitosis throughout the embryo. Neither this study, nor that of Lehner et al. (1991), who used the heat shock promoter to drive expression of cyclin A, commented upon any adverse effect of heat shock on cell cycle progression. As we are also interested in the use of this same promoter to study the effects of the ectopic expression of other cell cycle genes, we have carried out an investigation of the effects of heat shock administered during cell cycle 14 on morphogenesis and cell division in wild-type Drosophila embryos. In this paper, we report that such a heat shock pulse also has a direct effect upon the cell cycle, disturbing the timing of the divisions in the mitotic domains, and 
leading to an artificial synchronisation of cells that would otherwise enter mitosis at different times. Taken together, these observations call for caution in the interpretation of data regarding the control of the cell cycle in Drosophila based on the use of the $h s p 70$ promoter.

\section{MATERIALS AND METHODS}

\section{Heat shock procedure}

Embryos were dechorionated in $100 \%$ bleach and thoroughly rinsed in distilled water (at room temperature). They were then placed under $0.7 \% \mathrm{NaCl}$ and viewed using a dissecting microscope. Embryos that were at the particular stage of development required were selected and transferred into 1001 of $0.7 \% \mathrm{NaCl}$ in a well of a 96-well micro-titre plate, and were given a $30 \mathrm{~min}$ heat shock at $37^{\circ} \mathrm{C}$ in a 'PREM' PCR machine (LEP Scientific) in which the rate of temperature change is approximately $1 \mathrm{deg}$. $\mathrm{C}$ per second. Following heat shock the embryos were allowed to recover at $25^{\circ} \mathrm{C}$ for the times specified in the text. Although we have seen perturbed timing of divisions in all experiments in which embryos were heat shocked, we initially noted some degree of variability in the extent of synchrony depending upon whether the heat shock was given in a $37^{\circ} \mathrm{C}$ room or in a water bath, and also upon the type of vessel used. This could reflect the previous observations of Lindquist (1980) who reported that the effects of heat shock varied not just with temperature, but with the speed of the temperature increase. The use of a microtitre plate and PCR machine enabled us to standardise the experimental conditions.

\section{Fixation and immunostaining of embryos}

Embryos were fixed and prepared for staining as described in Whitfield et al., 1990. DNA was stained using Hoechst 33258 at $1 \mu \mathrm{g} / \mathrm{ml}$ or PDI also at $1 \mu \mathrm{g} / \mathrm{ml}$. Immunostaining of cyclin A, cyclin B, tubulin and Bx63 antigen was carried out as previously described by Maldonado-Codina and Glover (1992). Observations were made using a Zeiss Standard microscope equipped for epifluorescence, or a Nikon Optiphot attached to the Bio-Rad MRC600 confocal microscope head.

\section{RESULTS}

We wished to use the $h s p 70$ promoter to study the effects of the ectopic expression of cell cycle control genes in cellularised Drosophila embryos. We decided first to study the effects of 30 minute heat shocks upon wild-type embryos. These conditions are similar to those used in the experiments shown by Edgar and O'Farrell (1990) studying the ectopic expression of stg. In their experiments, however, heat shock was administered to embryos at timed intervals after egg deposition. As we were concerned to be able to identify the developmental stage as precisely as possible, we dechorionated embryos prior to heat treatment allowing us to select individual embryos staged by their morphological appearance as being in 'S-phase', 'early $\mathrm{G}_{2}$-phase', or 'late $\mathrm{G}_{2}$-phase' of cycle 14 (Fig. 1) (Edgar and O'Farrell, 1990). We have confirmed that the effects we describe can be seen irrespective of whether or not embryos have been dechorionated.

\section{Heat shock during S-phase delays entry into mitosis}

The S-phase of cycle 14 takes place during a 35-45 minute

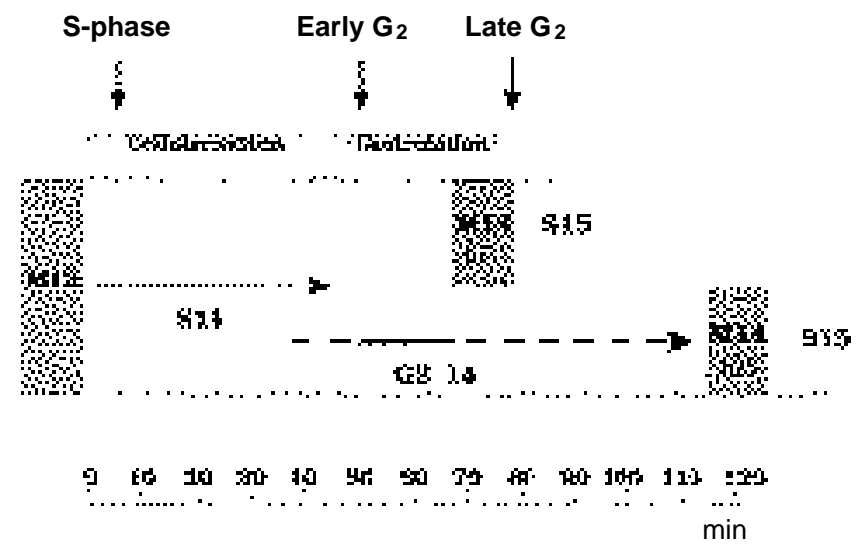

Fig. 1. The timing of cell cycle 14 in relation to cellularisation and gastrulation The final mitosis within the syncytial Drosophila embryo (M13) occurs synchronously, following which nuclei undertake the 14th S-phase whilst undergoing cellularisation. The 14th mitoses occur in a series of 27 domains of which just two,

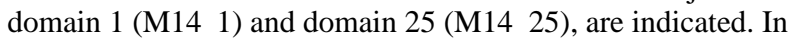
this study, embryos were selected at the three indicated morphological stages: embryos at the early stages of cellularisation were taken to be in 'S-phase'; embryos showing the early gastrulation movements of cephalic furrow formation are designated 'early $\mathrm{G}_{2}$-phase'; and embryos in which gastrulation is complete and the pole cells have invaginated are designated 'late $\mathrm{G}_{2}$-phase'. The exact stage of S-phase is difficult to assess using the extent of cellularisation as a marker. Consequently embryos which have been staged in this way could vary in age by as much as $30 \mathrm{~min}$. In addition to the effects we describe in the text upon cell cycle progression, we also observed that heat shock causes extensive morphogenetic aberrations. Following 45-60 min of recovery from a heat shock administered in S-phase, two broad morphological categories of embryos can be observed: one in which morphogenesis appears relatively normal, and the other in which gastrulation movements are virtually halted, or in which the order of events is grossly perturbed. Upon recovery, the former category displayed reasonably normal patterns of division with a slight perturbance in the sequence in which the later domains divide. Domain 11, for example, usually initiates division fourteen from discrete foci, which then expand outwards and join to form a thick band that runs along the side of the embryo. After a heat shock we often observe domain 11 to divide virtually synchronously. The second category showed totally abnormal development and division patterns. We presume that the relatively normal embryos represent a population that received a heat shock at a later stage of S-phase when they had already passed through a critical 'sensitive' period. Such a 30 min heat shock during Sphase results in $80 \%$ of the embryos dying before hatching. Less extensive morphogenetic abnormalities are seen following heat shock in $\mathrm{G}_{2}$. The heat shocked embryos shown in Fig. 7 exemplify the extent of morphogenetic abnormalities following heat shock in $\mathrm{G}_{2}$. If the heat shock is administered during early $\mathrm{G}_{2}$ there is less lethality than when administered during S-phase, with only $30 \%$ of embryos dying before hatching.

period immediately following mitosis 13 (Edgar and O'Farrell, 1990). Throughout this S-phase period, membranes grow down from the surface of the embryo to surround the nuclei, which become incorporated into individual cells. Embryos that were in the early stages of cellularisation were given a heat shock at $37^{\circ} \mathrm{C}$ for $30 \mathrm{~min}-$ utes and then left to recover at $25^{\circ} \mathrm{C}$ for $0-60$ minutes 
before fixing and staining with Hoechst. All cells were found to be in interphase immediately following this treatment as judged by the organisation of their microtubules (not shown). However, all the nuclei showed abnormally high levels of chromatin condensation. When such embryos were allowed a 30 minute recovery period at $25^{\circ} \mathrm{C}$, we found gastrulation movements had begun, and in most cases the pole cells had invaginated. One would nor- mally see divisions in the early mitotic domains at this developmental stage. However, in these embryos all the cells remained in interphase (Fig. 2). Furthermore, their nuclei still exhibited a high degree of chromatin condensation, although this had decreased to some extent during the 30 minute recovery period. We also noted a detrimental effect of heat shock upon the viability of embryos during this period (see legend to Fig. 1).

\section{HEAT SHOCKED}

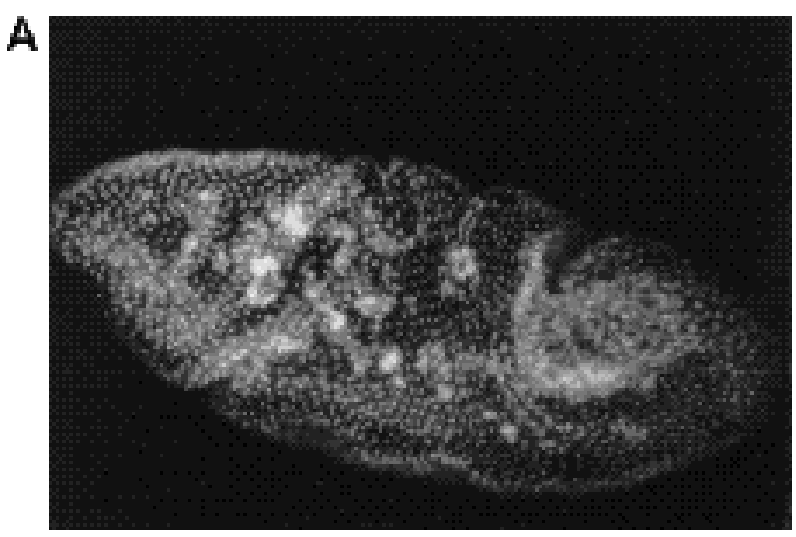

B
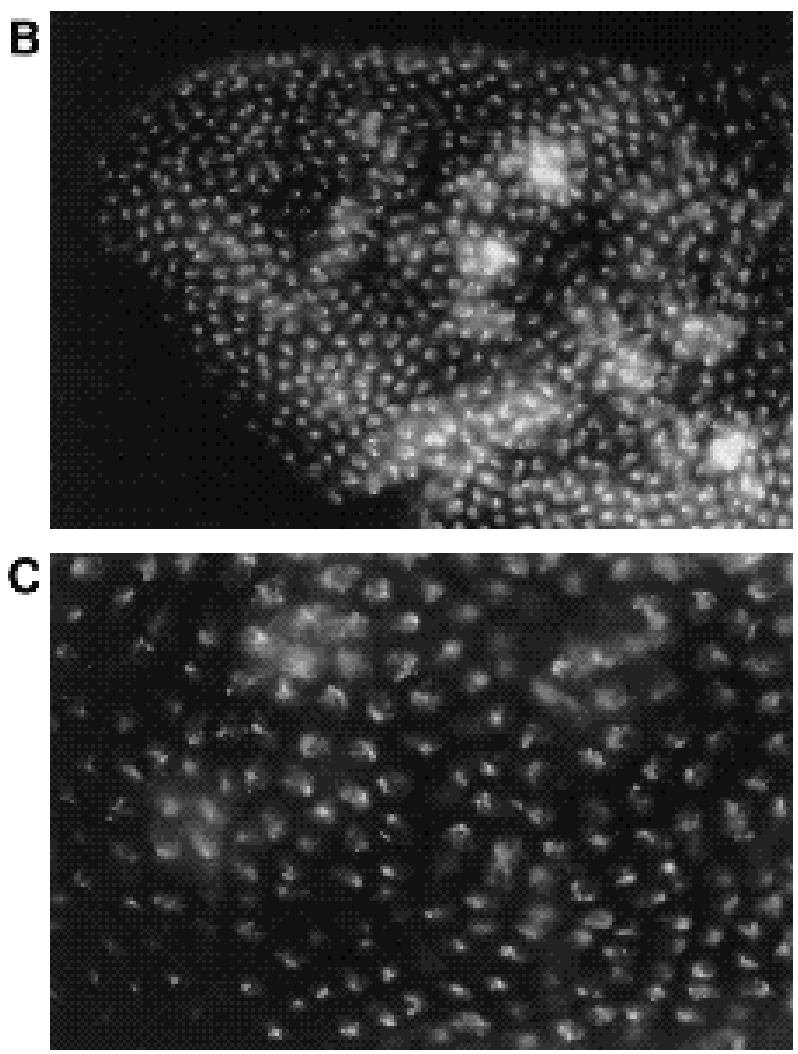

UNTREATED

D

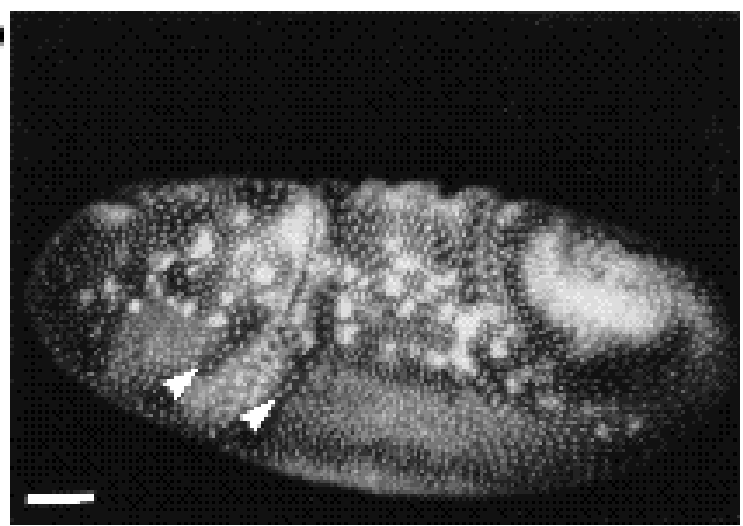

E

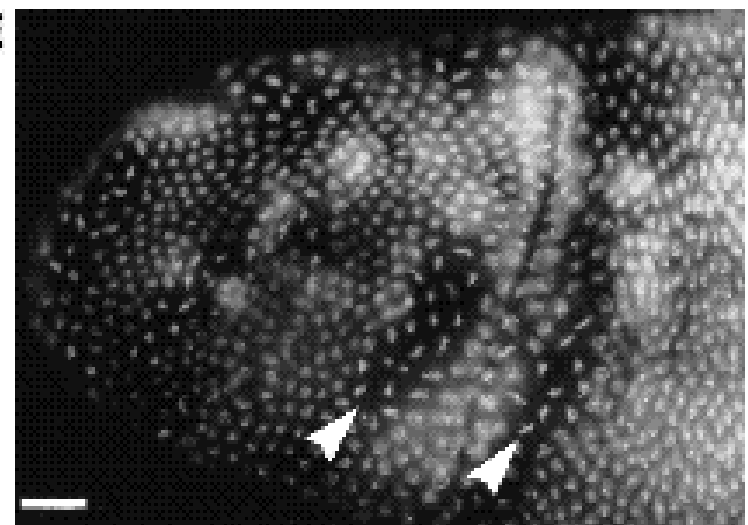

$\mathbf{F}$

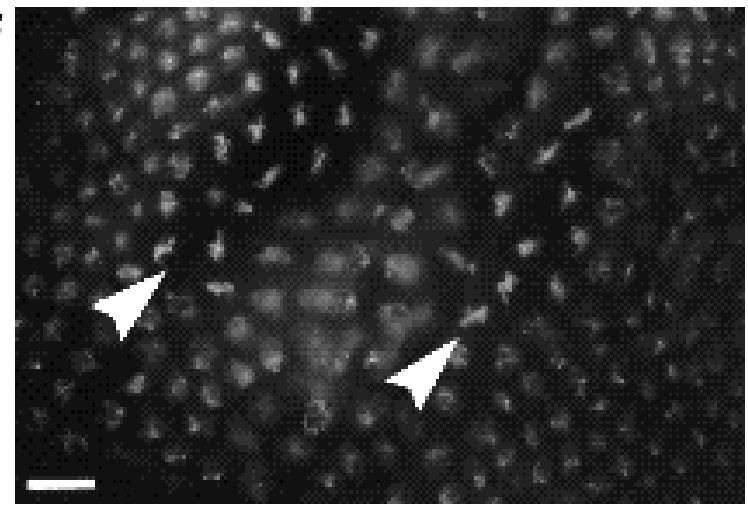

Fig. 2. Heat shock during S-phase delays entry into mitosis. (A-C) show different magnifications of an embryo that received a heat shock pulse during S-phase of cycle 14 , and was allowed $30 \mathrm{~min}$ of recovery at $25^{\circ} \mathrm{C}$. (D-F) show equivalent magnifications of an untreated embryo at a similar stage of development. All the cells in the heat shocked embryo remain in interphase, even though the embryo has clearly undergone gastrulation movements and reached a stage of morphogenesis at which the early domains should be dividing. The untreated control embryo is at a similar stage of morphogenesis and clearly shows domains 1-6 in mitosis. The arrowheads in (D-F) point out two of these domains, 5 and 6, which are undergoing mitosis. Note also the high chromatin condensation in interphase arrested nuclei in the heat shocked embryos, even after a 30 min recovery period. Embryos were stained to reveal DNA using Hoechst 33258 . Bars in D, E and $\mathrm{F}$ represent 50, 25 and $10 \mu \mathrm{m}$, respectively. 


\section{Heat shock in $\mathrm{G}_{2}$ can synchronise mitotic domains}

In order to study the effect of heat shock upon embryos in early $\mathrm{G}_{2}$ of cycle fourteen, i. e. before any domains enter mitosis, we collected embryos just as the cephalic furrow was forming. The recovery of the embryos from a 30 minute heat shock is shown in Fig. 3. Immediately after heat shock (Fig. 3A-C) all the cells were in interphase even though these embryos have reached a stage of morphogenesis at which the early domains should be undergoing mitosis. It appears therefore, that heat shock delays mitosis while allowing continued morphogenesis. We noted, however, that the nuclei all showed an abnormally high degree of chromatin condensation, as is also observed when heat shock is administered during S-phase (see above). Following a 10 minute recovery period the proportion of cells in the embryos that are in mitosis is striking (Fig. 3D-F). The majority of the cells in the cephalic region together with a
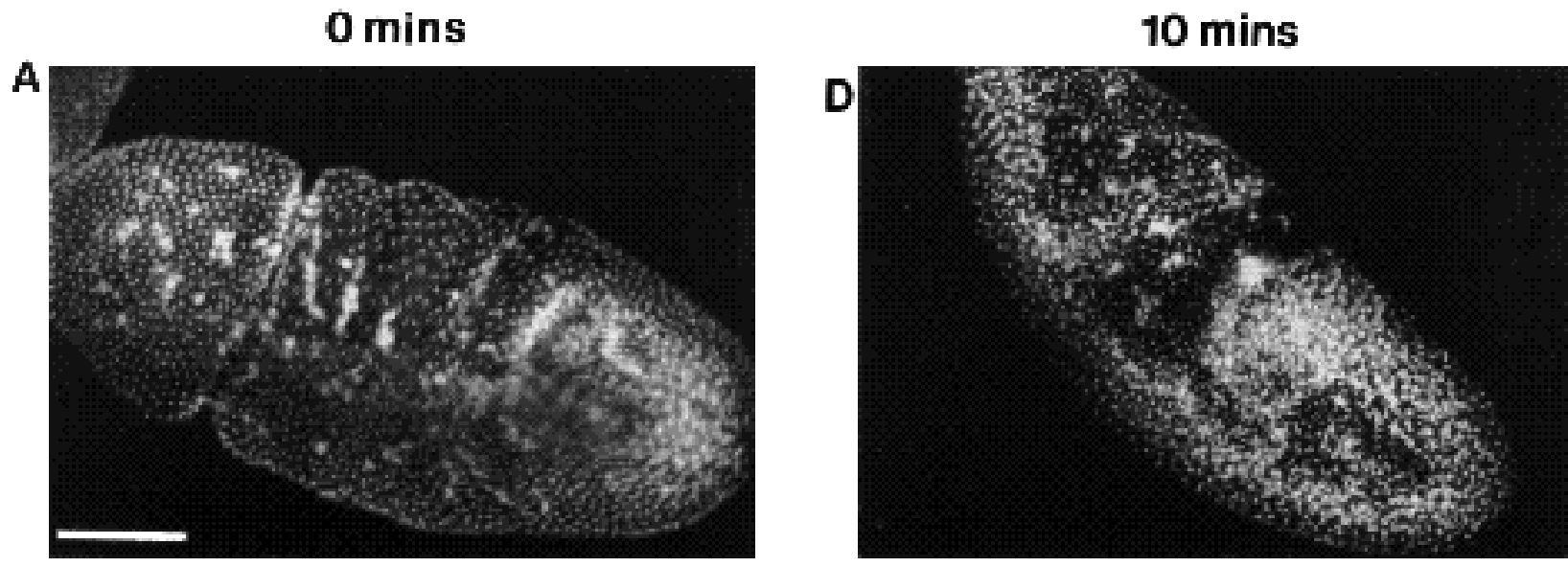

B

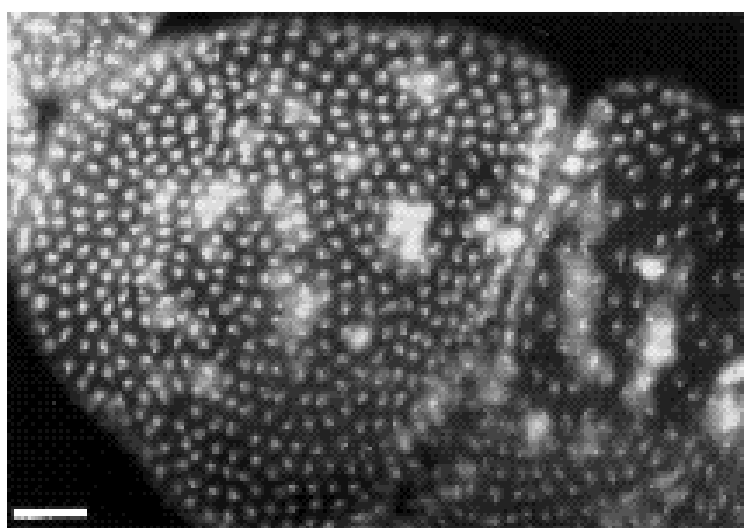

E
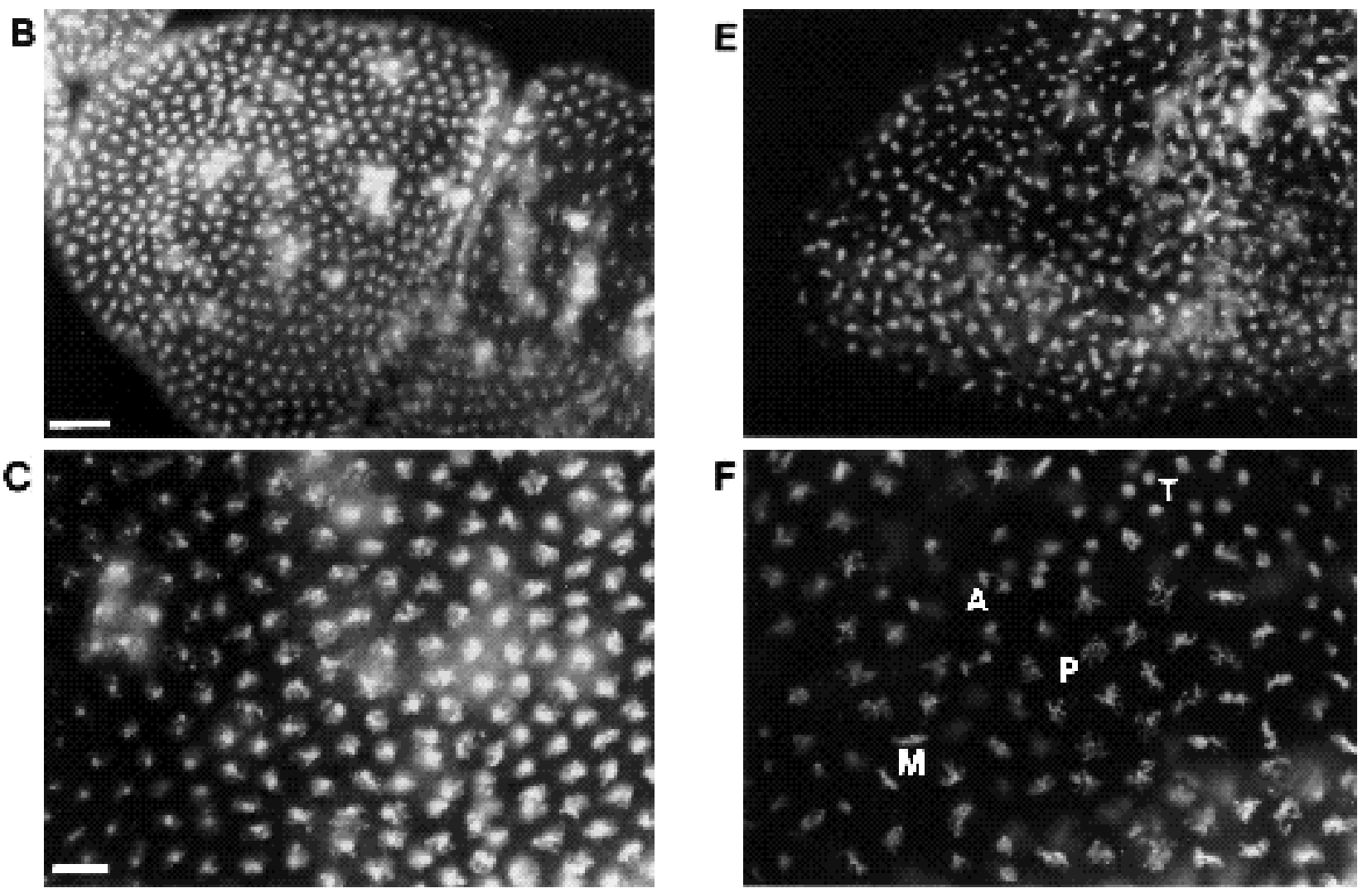

Fig. 3. Heat shock during $\mathrm{G}_{2}$ results in mitosis in all of the early domains. This Fig. shows two embryos fixed 0 min (A-C), and 10 min (D-F) after receiving a heat shock at the start of $\mathrm{G}_{2}$. Immediately following a heat shock in $\mathrm{G}_{2}(\mathrm{~A}-\mathrm{C})$ all the cells in the embryo remain in interphase whilst gastrulation movements have clearly advanced during the heat shock period. The early mitotic divisions should, at this stage of morphogenesis, be underway (compare to untreated control in Fig. 2, D-F). Following a 10 min recovery period at $25^{\circ} \mathrm{C}(\mathrm{D}-\mathrm{F})$ a large proportion of the cells enter mitosis synchronously. The higher power micrographs of the cephalic region $(\mathrm{E}$ and $\mathrm{F})$ show the majority of cells in mitosis. Cells at different mitotic phases are labelled in (F): p, prophase; m, metaphase; a, anaphase; and t, telophase. The embryos were stained to reveal DNA with Hoechst 33258. Bars in A, B and C represent 100, 25 and $10 \mu \mathrm{m}$, respectively. 
substantial proportion of cells from the rest of the embryo appeared to be in metaphase and anaphase. These dividing cells correspond to those domains delayed in interphase by the heat shock, together with cells in domains showing their correct temporal sequence of divisions. Consequently, most of the cephalic region and large parts of the body, corresponding to domains 10 and 11 , are now all dividing together. The perturbation of the temporal sequence can lead to an even more dramatic synchronisation of cell division. For example, all of the cells visible in the embryo in Fig. 4 are in prometaphase including the amnioserosa (labelled A in Fig. 4A), and domain B in the cephalic region, which would not normally enter M-phase again (labelled B Fig. 4A). Following a 30 minute recovery period from heat shock the embryos looked normal, with all of the cephalic region having divided, and divisions still occurring in the later domains, $\mathrm{N}$ and 19. After a 1 hour recovery period, the embryos look normal and cycle 15 appears to take place with the correct timing and patterns in relation to the morphogenetic development of the embryo.

Similar effects are seen if heat shock is administered later in $G_{2}$, when gastrulation is completed (see Fig. 1) and when the early domains have already initiated mitosis. Such an embryo is shown in Fig. 5. The early domains, that have completed cycle 14, can be seen as areas of increased cell density (indicated by arrowheads). These cells and the surrounding ones that have not undertaken the 14th division are all in interphase as can be seen from the nuclear localisation of the Bx63 antigen, and the staining of cytoplasmic microtubules. This should be contrasted with an untreated embryo at a comparable stage of morphogenesis (Fig. 5D,E). In this embryo, the mitotic domains can be seen as areas in which the RB188 staining is no longer strongly nuclear, but diffuse, and in which microtubules are organised into mitotic spindles.

\section{Degradation of the cyclin A and B proteins is delayed in the divisions that follow heat shock}

We have previously described the relative stages of the cell cycle at which cyclins A and B are degraded in the cellularised Drosophila embryo and in cells of the larval central nervous system (Whitfield et al., 1990). Cyclin A is normally high in the cytoplasm of interphase cells, becomes nuclear in prophase cells but is then abruptly degraded, such that neither metaphase nor anaphase cells show staining. Cyclin B protein is usually degraded a little later during metaphase, such that approximately $50 \%$ of metaphase cells show cyclin B staining, with no staining seen in anaphase cells.

Immediately after heat shock in early $G_{2}$, the level of both cyclin A (Fig. 6B) and cyclin B (Fig. 6D) remained high in cells throughout the embryo, reflecting that they are delayed in interphase. These embryos have reached a morphological stage at which divisions should be occurring in the early domains. The control embryos (Fig. 6E-H) clearly show the expected pattern of early divisions. Domains that have just completed the fourteenth division or are in the process of dividing show no staining either of cyclin A or cyclin B. The cells of the later dividing domains remain in interphase and show high cytoplasmic levels of both proteins.
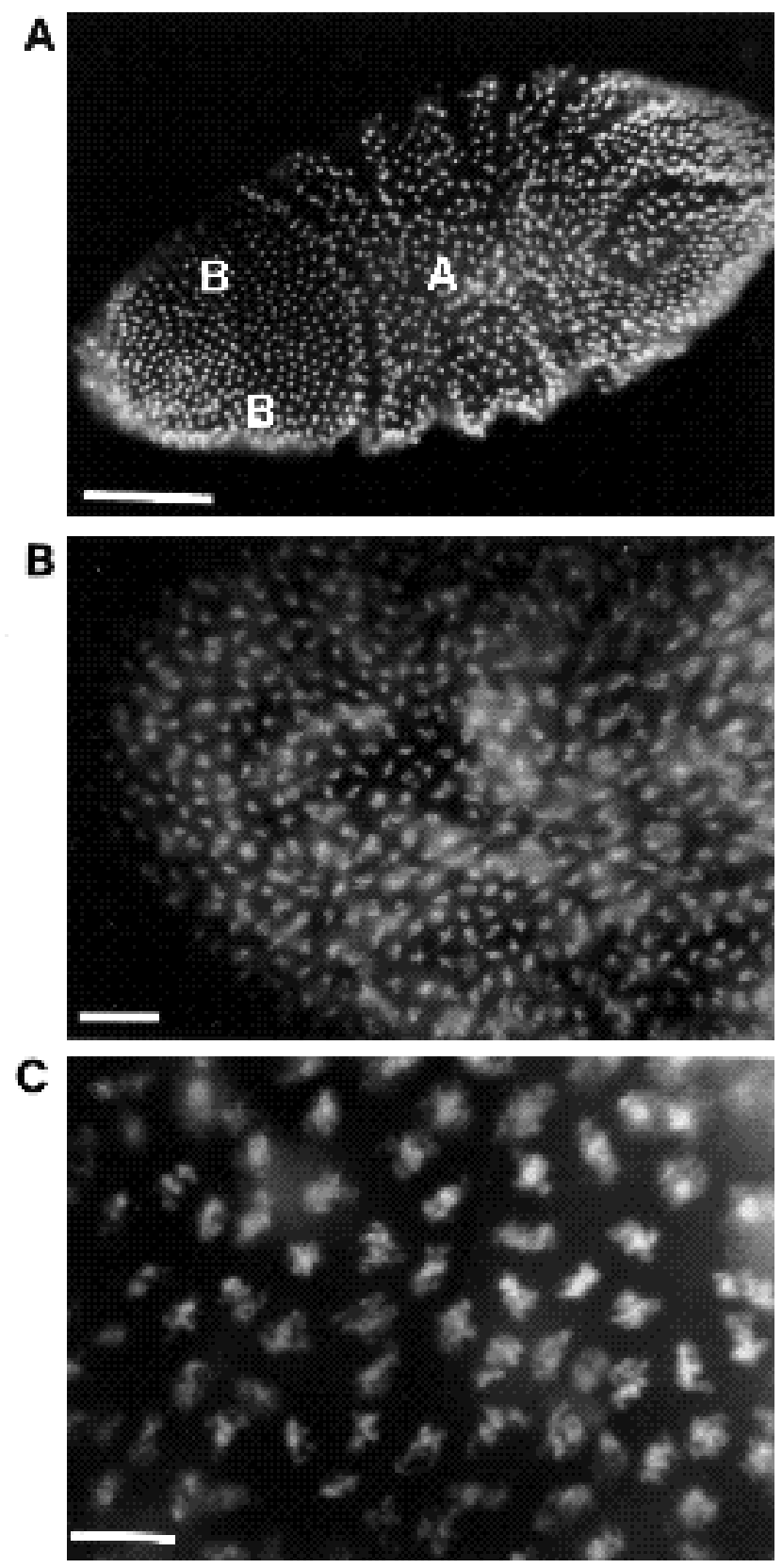

Fig. 4. Synchronous prometaphase throughout an embryo heat shocked in $\mathrm{G}_{2}$. The embryo pictured in these micrographs was given a heat shock at an early stage of $\mathrm{G}_{2}$, and allowed a $7 \mathrm{~min}$ recovery period at $25^{\circ} \mathrm{C}$. All the cells in the embryo are in prometaphase; including the cells of the amnioserosa and domain $\mathrm{B}$ in the cephalic region (labelled A and B respectively in (A)), which are normally arrested at $\mathrm{G}_{2}$ of cycle 14 . The embryo was stained with Hoechst 33258. Bars in A, B and C represent 100, 20 and $10 \mu \mathrm{m}$, respectively.

In the almost synchronous mitoses that occur following a ten minute recovery period the pattern of cyclin A destruction does not appear to occur with the normal timing. However, in untreated embryos, we see high levels of cyclin A in less than $10 \%$ of cells showing a metaphase configuration of chromosomes, following recovery from heat shock $65 \%$ of metaphase cells have high levels of cyclin A (Fig. 

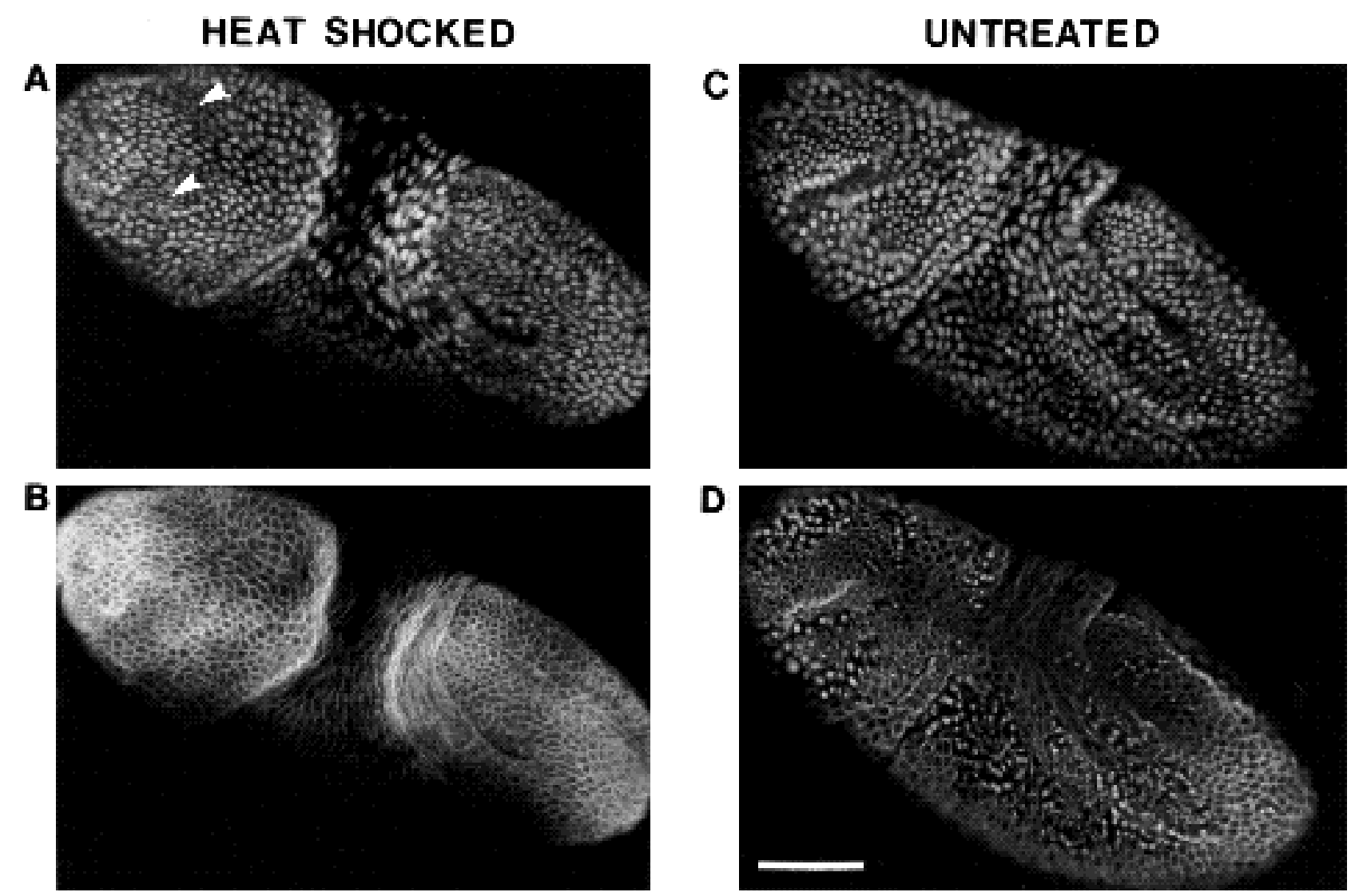

Fig. 5. Interphase arrest immediately following heat shock administered in late $\mathrm{G}_{2}$. (A) and (B) show an embryo immediately following a heat shock administered following the initiation of divisions in domains 1-5. The embryo has been stained to reveal the $190 \mathrm{kDa}$ nuclear/centosomal antigen first identified by the monclonal antibody Bx63 (Frasch et al., 1986; Whitfield et al., 1988) (A). This antibody recognises a $190 \mathrm{kDa}$ protein that is nuclear in interphase and found in centrosomes during mitosis. The second immunolabel is the monoclonal antibody YL1/2 that recognises tubulin (Kilmartin et al., 1982) (B). A similarly stained, untreated control embryo at an equivalent stage of morphogenesis is shown in (C) and (D). The heat shocked embryo has completed divisions in domains 1-5, which can be recognised as areas of increased nuclear density, e. g. arrowheads in (A). However, no new mitoses have been initiated during the heat shock period. This absence of mitotic activity is dramatically demonstrated by the lack of spindles in the heat shocked embryo and by the nuclear association of the Bx63 antigen (B). This should be compared to the untreated control embryo (D) which shows numerous spindles, indicating that divisions are normally occurring in numerous mitotic domains at this morphological stage. Bar, $100 \mu \mathrm{m}$.

7 , see arrowheads). Once again a striking proportion of cells are undergoing mitosis in this embryo stained to reveal cyclin A. Cyclin B destruction also appears to be delayed in the divisions that follow heat shock. Rather than there being high levels of cyclin B in 50\% of metaphase cells, all metaphase cells show high levels (Fig. 7). It is also our impression that cyclin B is not degraded to the extent seen in untreated embryos immunostained using the same antibody.

\section{DISCUSSION}

We are surprised that the effects we describe on wild-type embryos have not been reported previously since the heat shock promoter has been used to drive the ectopic expression of cell cycle regulatory proteins (Edgar and O'Farrell, 1990; Lehner and O'Farrell, 1991). Edgar and O'Farrell (1990) used heat shock to investigate the effects of the ectopic expression of the $c d c 25$ homologue string from the $h s p 70$ promoter. They observed that following the temperature-induced expression of stg throughout the embryo in the $\mathrm{G}_{2}$-phase of cycle 14 , mitotic figures could be found in all cells. Furthermore, cyclin A was degraded

Fig. 6. Cyclin A and B remain high in the interphase arrest following a heat shock. This Fig. shows the distribution of cyclin $A$ and cyclin B in embryos immediately following a 30 min heat shock, compared with that in untreated control embryos. (A) and (B) show propidium iodide and anti-cyclin A staining, respectively, of an embryo immediately following a heat shock administered during early $\mathrm{G}_{2}$. The respective $(\mathrm{E})$ and $(\mathrm{F})$ show propidium iodide and anti-cyclin A staining of an untreated embryo of similar age. The interphase arrest observed in the heat shocked embryo is clearly reflected by the high level of cyclin A in all the cells (B), compared with the untreated embryo that shows regions of cyclin degradation in cells that have completed dividing. (C) and (D) show an embryo immediately following a heat shock during early $\mathrm{G}_{2}$ stained with propidium iodide and anti-cyclin $\mathrm{B}$ antiserum, respectively. An untreated embryo stained with propidium iodide $(\mathrm{G})$ and anti-cyclin $\mathrm{B}(\mathrm{H})$ is also shown. The interphase arrest resulting from heat shock is shown by the overall high level of cyclin B (D). 
throughout the embryo during these mitoses, which were immediately followed by the entry of all cells into S-phase. In these studies, Edgar and O'Farrell applied heat shock to embryos carrying the $h s$-stg construct at a comparable stage to the treatments used in our present study. As we observe considerable synchronisation of mitosis in wild-type embryos following heat shock, it seems that the synchronisation observed by Edgar and O'Farrell is unlikely to be

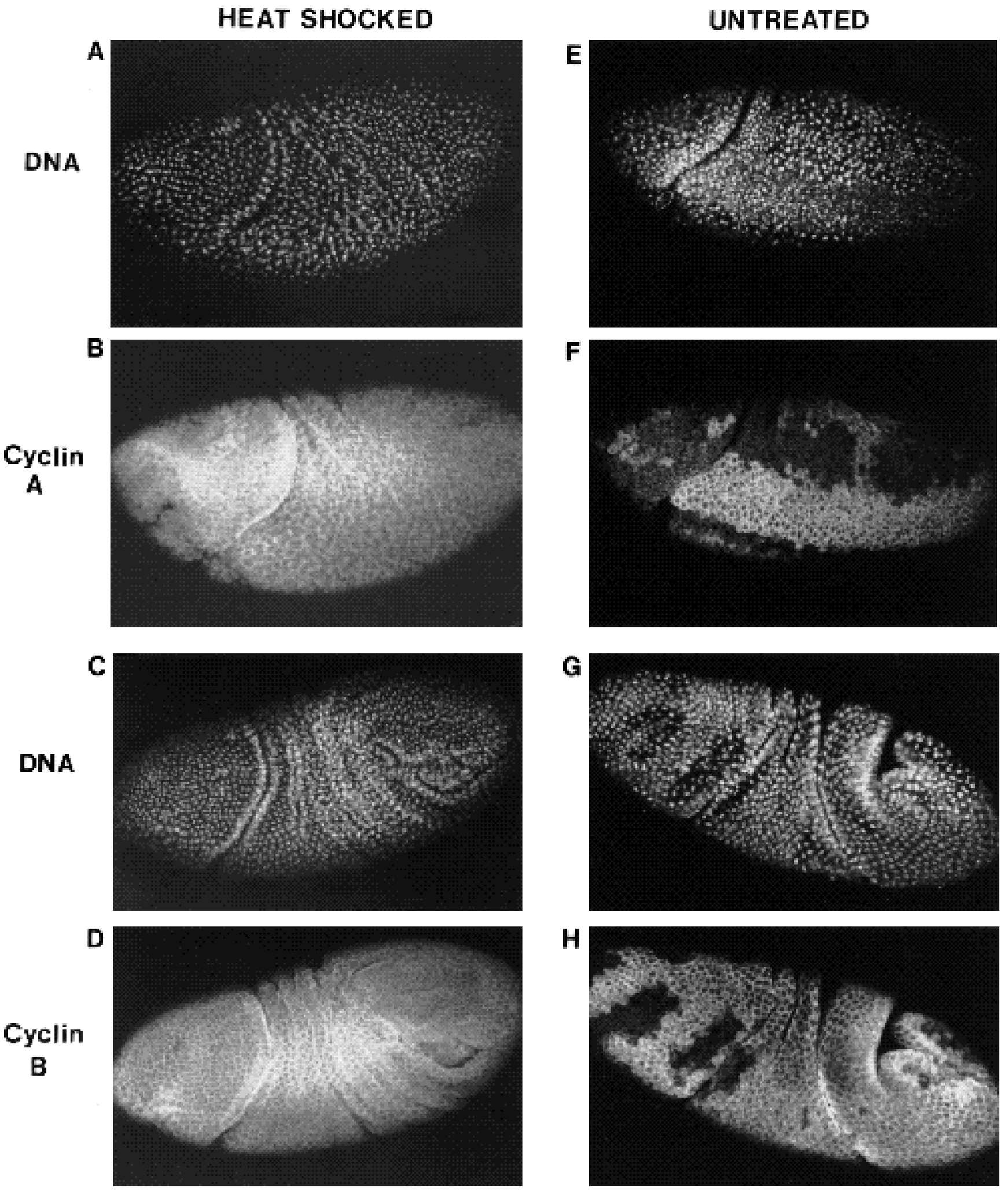

Fig. 6 
Cyclin A

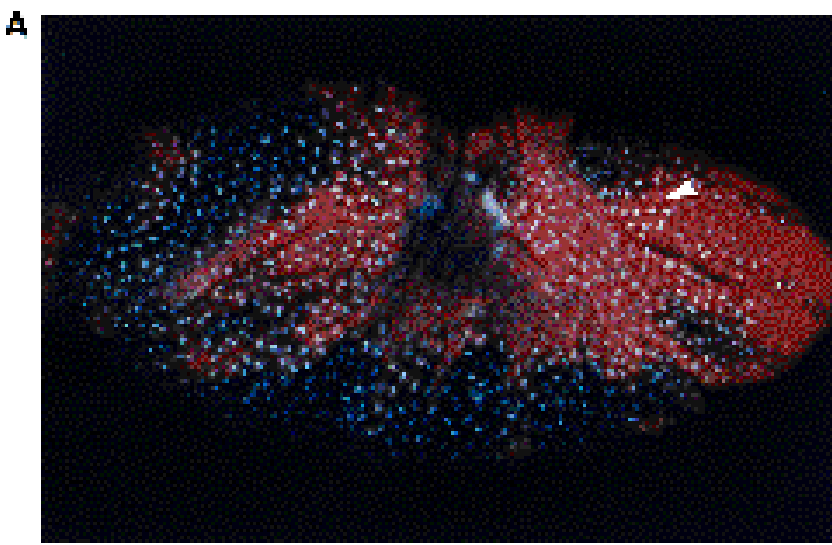

B

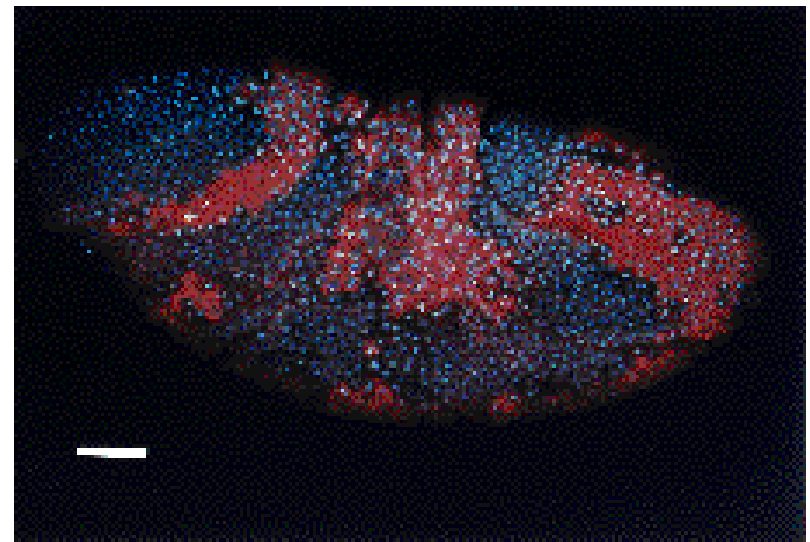

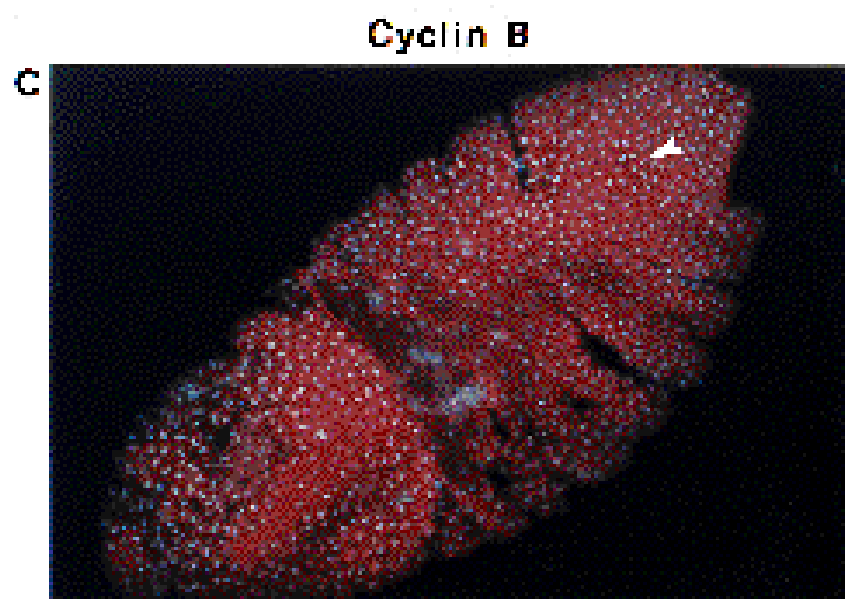

D

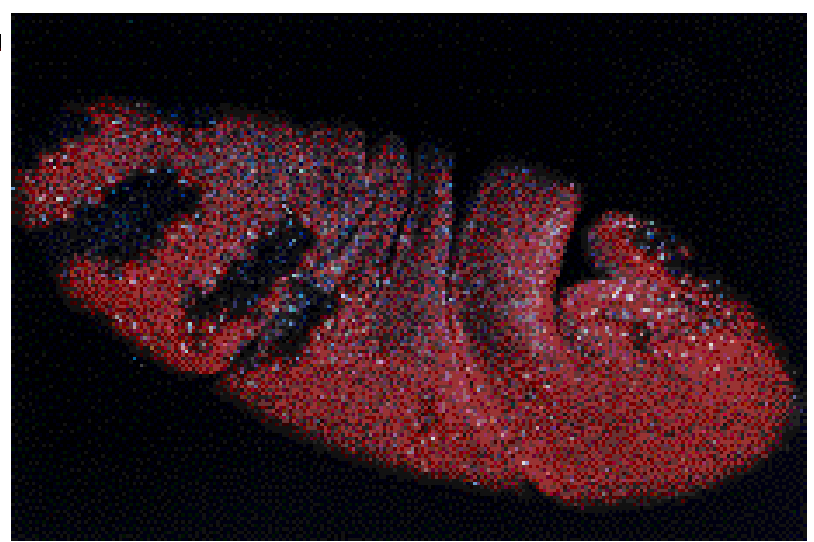

Fig. 7. Behaviour of cyclin A and B in the divisions that follow a heat shock. (A) and (C) show embryos that have been given a heat shock in early $\mathrm{G}_{2}$ and allowed a 10 min recovery period. (B) and (D) show untreated embryos at a comparable morphological stage of development. Embryos have been stained with anti-cyclin A antibodies (red stain, (A) and (B)), anti-cyclin B antibodies (red stain, (C) and (D)), and counterstained to reveal DNA (blue). Note that mitotic figures are present throughout the embryo in (A) and that cyclin A is at high levels in $65 \%$ of the metaphase cells (arrowhead points to an example). Most cells in the cephalic region of the embryo in (C) are undergoing mitosis, but the timing and extent of cyclin B degradation is not normal. All metaphase cells have high levels of cyclin B, which does not appear to be fully degraded following mitosis (arrowhead points to an example). The embryos in (A) and (C) show morphological abnormalities typical of embryos heat shocked in early $\mathrm{G}_{2}$ of cycle 14 . The embryo in (A) shows an unusual furrow in the cephalic region. This furrow may have been caused by the extensive simultaneous cell divisions occurring in this region pushing the nondividing domain B inwards. The embryo in $(\mathrm{C})$ on the other hand appears to have undergone relatively normal morphogenesis in the cephalic region, but germ band elongation has not occurred to an equivalent extent.

due to the ectopic expression of stg alone. However, in the data they present, the mitoses induced by hs-stg are highly synchronised throughout the embryo, as is cyclin degradation. In our experiments with wild-type embryos, on the other hand, we have observed embryos in which all cells are undergoing mitosis, and others in which the synchronous divisions are restricted to the early domains depending upon the point at which heat shock was given. Furthermore, we do not see synchronous degradation of cyclin, rather this process appears delayed. It is possible that the extent of the effect of heat-shock upon the cell cycle is critically dependent upon the conditions used (see Materials and Methods). Nevertheless, it remains important to determine the extent to which heat shock per se, and the ectopic expression of stg contribute to synchronising cycle 14 mitoses.

Lehner et al. (1991) have found that the ectopic expression of cyclin A from a heat shock promoter fol- lowing the 16th round of mitoses does not affect the progression through S-phase as judged by the pattern of BrdU incorporation. The exception are cells of the amnioserosa, which unexpectedly showed BrdU incorporation. They attributed this to be a consequence of ectopic cyclin A expression since cells of this tissue normally cease division following S14. However, we find that these $\mathrm{G}_{2}$ amnioserosa cells of wild-type embryos are still able to undertake chromosome condensation following heat shock in cycle 14 . Furthermore, we have been able to see BrdU incorporation into some of these cells in wild-type embryos following heat shock administered under conditions comparable to those of Lehner et al. (1991) (data not shown). It is possible that Lehner and colleagues (1991) may not have observed this effect, if it were dependent upon the precise way in which heat shock is administered (see Materials and Methods). Moreover, it looks as though a higher proportion of amnioserosa cells incorporate BrdU in embryos car- 
rying the $h s$-cyclin $A$ construct, and so we suggest that cyclin A may accentuate this phenomenon, although it is not entirely responsible for it. This interpretation may find support from the observations that amnioserosa cells also appear to undertake DNA synthesis following the heat shock treatment of cycle 14 embryos carrying the hs-stg construct (Edgar and O'Farrell, 1990).

The effects we observe heat shock to have on cell cycle progression are likely to be a consequence of the disruption of several cellular events. The most severe effects that we observe in S-phase could reflect the fact that this is the major period of chromatin assembly and could be a consequence of the known effects of heat shock on chromatin structure brought about by changes in the post-translational modifications of histones. Nuclei could be particularly sensitive to such stress during early embryogenesis as they are still undergoing rapid rounds of DNA replication in which the chromosomes contain multiple replication loops at approximately $30 \mathrm{~kb}$ intervals (Blumenthal et al., 1973). In cells that are in $\mathrm{G}_{2}$-phase at the time of heat shock, cell cycle progression may be most affected by the inhibition of ongoing transcription and translation. The delay in entering $\mathrm{M}$ may be a specific consequence of the inhibition of transcription of the $c d c 25$ homologue $s t g$, and translation of these transcripts. However, our preliminary experiments indicate that stg RNA does not appear to be degraded as a result of heat shock (not shown), perhaps explaining the rapid recovery that we observe after heat shock. The cell cycle progression of $\mathrm{G}_{2}$ cells already committed to enter mitosis by the activation of $\mathrm{p} 34^{\mathrm{cdc} 2}$ kinase, may become blocked if the cytoskeleton were to become disrupted, as shown to occur with intermediate filaments by Walter et al. (1990). Structural and functional alterations to the centrosome are also known to occur following heat shock (Debec et al., 1990). Finally, heat shock is known to induce the synthesis of ubiquitin and of some of its conjugating enzymes (Ozkaynak et al., 1987; Finley et al., 1987). This process has a cell cycle role at least in S. cerevisiae where one of the genes responsible for transferring ubiquitin to an appropriate substrate corresponds to $C D C 34$, a gene required for the G1-S transition (Jentsch et al., 1987; Goebl et al., 1988). The ubiquitination of proteins frequently targets them for degradation. Indeed, ubiquitination of the mitotic cyclins appears to be responsible for their degradation at the metaphase-anaphase transition (Glotzer et al., 1991). However, our observations show that the degradation of cyclins A and B does not occur prematurely following heat shock of Drosophila embryos in $\mathrm{G}_{2}$ of cycle 14. On the contrary, it appears to be delayed. The persistence of both cyclins in cells undertaking mitosis upon recovery from heat shock again raises the question of whether cyclin degradation is a requirement for this transition (Murray et al., 1989), or is a consequence of it (Whitfield et al., 1990).

The finding that heat shock per se can have a profound effect upon the progression through the mitotic cycle is not new. Indeed Scherbaum and Zeuthen (1954) found that repeated heat shocks could be used to synchronise the cell division cycle in cultures of Tetrahymena. Heat shock has also long been known to have effects in Drosophila development. If embryos are exposed to heat shock during crit- ical periods, a number of defects termed phenocopies are later seen that resemble the effects of mutations (Goldschmidt, 1935; Gloor, 1947). Thus heat shock given around the time of blastoderm formation can result in bithorax phenocopies (Capdevila and Garcia-Bellido, 1978; Santamaria, 1979; Dura and Santamaria, 1983), whereas heat shocks after gastrulation can induce specific patterns of segmentation disruption (Eberlein, 1986). Nevertheless, the heat shock promoter has found extensive use in analysing the effects of ectopic expression of many developmentally regulated genes in Drosophila, and has provided valuable insights into the regulation of development. However, our experiments show the need to exercise great caution in order to fully account for the direct effects of heat shock per se upon cell division, before reaching any conclusion based on the use of the heat shock promoter as a means of directing the expression of either wild type or mutant cell cycle genes.

We thank Hiroyuki Ohkura for his initial observations of synchronous mitoses in heat shocked cycle 14 embryos, and for his continued interest and discussion of our results. We also thank Cayetano Gonzalez and Luke Alphey for their comments on the manuscript. The work was supported by the Cancer Research Campaign.

\section{REFERENCES}

Blumenthal, A. B., Kreigstein, H. J. and Hogness, D. S. (1973). The units of DNA replication in Drosophila melanogaster Chromosomes. Cold Spring Harb. Symp. Quant. Biol. 38, 205-223.

Capdevila, M. P. and Garcia-Bellido, A. (1978). Phenocopy of bithorax mutants; genetic and developmental analysis. Wilhelm Roux Arch. EntwMech. Org. 185, 105-126.

Debec, A., Courgeon, A. M., Maingourd, M. and Maisonhaute, C. (1990). The response of the centrosome to heat shock and related stresses in a Drosophila cell line. J. Cell Sci. 96, 403-412.

Dura, J. M. and Santamaria, P. (1983). Heat shock induced phenocopies: cis-regulation of the bithorax complex in Drosophila melanogaster. Mol. Gen. Genet. 189, 235-239.

Eberlein, S. (1986). Stage specific embryonic defects following heat shock in Drosophila. Dev. Genet. 6, 179-197.

Edgar, B. A. and O'Farrell, P. H. (1990). The three postblastoderm cell cycles of Drosophila embryogenesis are regulated in $\mathrm{G}_{2}$ by string. Cell 62, 469-480.

Finley, D., Ozkaynak, E. and Varshavsky, A. (1987). The yeast polyubiquitin gene is essential for resistance to high temperatures, starvation, and other stresses. Cell 48, 1035-1046.

Foe, V. E. (1989). Mitotic domains reveal early commitment of cells in Drosophila embryos. Development 107, 1-22.

Foe, V. E. and Alberts, B. M. (1983). Studies of nuclear and cytoplasmic behaviour during the five mitotic cycles that precede gastrulation in Drosophila embryogenesis. J. Cell Sci. 61, 31-70.

Foe, V. E. and Alberts, B. M. (1985). Reversible chromosome condensation induced in Drosophila embryos by anoxia: visualisation of interphase nuclear organisation. J. Cell Biol. 100, 1623-1636.

Frasch, M., Glover, D. M. and Saumweber, H. (1986). Nuclear antigens follow different pathways into daughter nuclei during mitosis in early Drosophila embryos. J. Cell Sci. 46, 155-172.

Gloor, H. (1947). Phanokopie-Versuche mit Ather an Drosophila. Rev. Suisse Zool. 54, 637-708.

Glotzer, M., Murray, A. W. and Kirschner, M. (1991). Cyclin is degraded by the ubiquitin pathway. Nature 349, 132-138.

Goebl, M. G., Yochem, J. Jentsch, S., McGrath, J. P., Varshavsky, A. and Byers, B. (1988). The yeast cell cycle gene CDC34 encodes a ubiquitin-conjugating enzyme. Science 241, 1331-1335.

Goldschmidt, R. B. (1935). Gen und ausseengigenschaft (untersuchungan Drosophila). Z. indukt. Abstamm. Vererbungsl. 69, 38-131. 
Jentsch, S., McGrath, J. P. and Varshavsky, A. (1987). The yeast DNA repair gene RAD6 encodes a ubiquitin-conjugating enzyme. Nature 329, 131-134.

Kilmartin, J. V., Wright, B. and Milstein, C. (1982). Rat monoclonal antitubulin antibodies derived using a new non-secreting rat cell line. J. Cell Biol. 93, 576-582.

Lehner, C. F., Yakubovich, N. and O'Farrell, P. H. (1991). Exploring the role of Drosophila cyclin A in the regulation of S phase. Cold Spring Harb. Symp. Quant. Biol. 56, 465-475.

Lindquist, S. (1980). Varying patterns of protein synthesis in Drosophila during heat shock: implications for regulation. Dev. Biol. 77, 463-479.

Maldonado-Codina, G. and Glover D. M. (1992). Cyclins A and B associate with chromatin and the polar regions of spindles, respectively, and do not undergo complete degradation at anaphase in syncytial Drosophila embryos. J. Cell Biol. 116, 967-976.

McKenzie, S. L., Henikoff, S. and Meselson, M. (1975). Localisation of RNA from heat-induced polysomes at puff sites in Drosophila melanogaster. Proc. Nat. Acad. Sci. USA 72, 1117-1121.

McKenzie, S. L. and Meselson, M. (1977). Translation in vitro of Drosophila heat shock messages. J. Mol. Biol. 177, 279-283.

Murray, A. W., Solomon, M. J. and Kirschner, M. W. (1989). The role of cyclin synthesis and degradation in the control of maturation promoting factor activity. Nature 339, 280-286.

Ozkaynak, E., Finley, D., Solomon, M. J. and Varshavsky, A. (1987). The yeast ubiquitin genes: a family of natural gene fusions. $E M B O \mathrm{~J}$. 6, 1429-1439.
Pauli, D., Arrigo, A. P. and Tissieres, A. (1992). Heat shock response in Drosophila. Experientia 48, 623-628.

Ritossa, F. (1962). A new puffing pattern induced by temperature shock and DNP in Drosophila. Experienta 13, 571-573.

Santamaria, P. (1979). Heat shock induced phenocopies of dominant mutants of the bithorax complex in Drosophila melanogaster. Mol. Gen. Genet. 172, 161-163.

Scherbaum, O. and Zeuthen, E. (1954). Induction of synchronous cell division in mass cultures of Tetrahymena pyriformis. Exp. Cell Res. 6, 221-227

Spradling, A., Pardue, M. L. and Penman, S. (1977). Messenger RNA in heat shocked Drosophila cells. J. Mol. Biol. 109, 559-587.

Tissières, A., Mitchell, H. K. and Tracy, U. M. (1974). Protein synthesis in salivary glands of Drosophila melanogaster: relation to chromosome puffs. J. Mol. Biol. 84, 389-398.

Walter, M. F., Petersen, N. S. and Biessman, H. (1990). Heat shock causes the collapse of the intermediate filament cytoskeleton in Drosophila embryos. Dev. Genet. 11, 270-279

Whitfield, W. G., Gonzalez, C., Maldonado-Codina, G. and Glover, D. M. (1990). The A- and B-type cyclins of Drosophila are accumulated and destroyed in temporally distinct events that define separable phases of the $\mathrm{G}_{2}-\mathrm{M}$ transition. EMBO J. 9, 2563-2572.

Whitfield, W. G., Millar, S. E., Saumweber, H., Frasch, M. and Glover, D. M. (1988). Cloning of a gene encoding an antigen associated with the centrosome in Drosophila. J. Cell Sci. 89, 467-480.

(Received 17 February 1993 - Accepted 14 April 1993) 